\section{DOPRINOS ROLANJA U UČENJU OSNOVA ALPSKOG SKIJANJA}

CONTRIBUTION OF INLINE SKATING TO LEARNING BASICS OF ALPINE SKIING

\section{SAŽETAK}

Cilj ovog istraživanja bio je da se utvrdi doprinos rolanja usvajanju osnova alpskog skijanja. Istraživanjem je obuhvaćeno 139 ispitanika, koji su bili podijeljeni u dvije grupe kontrolnu $i$ eksperimentalnu. Ispitanici eksperimentalne grupe $(n=72)$ učestvovali su u školi vožnje rolera u trajanju od 10 dana, a ispitanici kontrolne grupe $(n=67)$ za to vrijeme nisu bili uključeni u sportske ili rekreativne programe. Prije i nakon provođenja škole vožnje rolera, svi ispitanici su podvrgnuti testiranju pomoću šest elemenata tehnike alpskog skijanja. Eksperimentalna grupa ispitanika imala je značajno bolje rezultate u elementima tehnike alpskog skijanja (4,09 vs. 3,29; $p=0.00)$. Rezultati ovog istraživanja ukazuju da vožnja rolera može pomoći boljem usvajanju znanja iz alpskog skijanja.

Ključne riječi: vožnja rolera, alternativni sport, znanje alpskog skijanja

\section{Igor Božić ${ }^{1}$, Vjekoslav Cigrovski ${ }^{2}$, Goran Bošnjak ${ }^{1}$, Vladimir Jakovljević ${ }^{1} \mathbf{i}$ Gorana Tešanović ${ }^{1}$}

${ }^{1}$ Fakultet fizičkog vaspitanja i sporta, Univerzitet u Banjoj Luci,

Bosna i Hercegovina

${ }^{2}$ Kineziološki fakultet, Sveučilišta

u Zagrebu, Hrvatska

Originalni naučni članak doi:10.5550/sgia.171301.se.BCBJT

UDK: 796.926

COBISS.RS-ID 6758936

Primljeno: 06.06.2017.

Odobreno: 03.07.2017.

Korespodencija: Mr Igor Božić

Fakultet fizičkog vaspitanja i sporta Univerzitet u Banjoj Luci

Bosna i Hercegovina igor.bozic@,ffvs.unibl.org

Sportlogia 2017, 13 (1), 1-8.

E-ISSN 1986-6119 


\section{UVOD}

U cilju što efikasnijeg učenja osnova alpskog skijanja, skijaši rekreativci treba da imaju adekvatnu opremu, odgovarajuće skijaške terene i, povrh svega, dobre instruktore skijanja koji će obuku provoditi u skladu sa verifikovanim/provjerenim programima škola alpskog skijanja. Programi škola alpskog skijanja treba da budu usklađeni sa potrebama polaznika, kao i sa uslovima u kojima se škola skijanja održava. Iako se širom svijeta koriste različiti programi za učenje osnova alpskog skijanja, svi ti programi su logički i sekvencijalno struktuirani, što znači da svaki naučeni element alpske škole skijanja predstavlja osnovu za učenje sljedećeg elementa (Cigrovski i Matković, 2015). Bez obzira koji program se koristi, svi polaznici treba da usvoje specifične kretnje, neophodne za kontrolisanje pokreta skija koji su važni za vrijeme zaokreta u alpskom skijanju (Tate, 2007). Rekreativno alpsko skijanje je sezonski sport za vrijeme zimskih mjeseci u alpskim skijaškim centrima. Pomenuti centri obično nude struktuirane programe učenja alpskog skijanja, ali u cilju što veće uspješnosti polaznika, važno je da oni budu adekvatno pripremljeni za skijanje (Wojtyczek, Pasławska i Raschner, 2014). Pored kondicione pripreme, ljudima se savjetuje da se nekoliko mjeseci prije skijanja bave sportovima koji imaju slične kretnje kao u alpskom skijanju (Roman, Miranda, Martinez i Jesus, 2009). Trening takmičara u alpskom skijanju redovno podrazumijeva alternativne sportove, koji opterećuju sportiste na sličan način kao skijaški treninzi. Vožnja rolera je jedan od mogućih vidova treninga van sezone (Kroll, Schiefermuller, Birklbauer i Muller, 2005). Očekuje se da kretnje koje se izvode tokom vožnje rolera poboljšavaju tehniku alpskog skijanja (Ropret, 2010). Sve navedeno ukazuje kako umijeće vožnje rolera može da doprinese učenju alpskog skijanja. Ako se pomenuta korelacija može dokazati, onda bi se vožnja rolera mogla uvrstiti u pripremni period kao kondicioni trening za alpsko skijanje. Cilj ovog istraživanja bio je da se utvrdi doprinos vožnje rolera učenju osnova alpskog skijanja kod skijaša rekreativaca.

\section{METODE}

Nakon dobijanja detaljnih informacija, ukupno 139 volontera dalo je svoju saglasnost za učešće u istraživanju. Prosječna starost ispitanika bila je 22.18 \pm 1.34 godina. Svi ispitanici bili su motorički sposobni, dobrog zdravlja, sa osnovnim umijećem alpskog skijanja. Metodom slučajnog izbora podijeljeni su u eksperimentalnu $(n=72)$ ili kontrolnu grupu $(n=67)$. Eksperimentalna grupa ispitanika pohađala je časove vožnje rolera u SkiBoo sportskoj akademiji, dok kontrolna grupa nije učestvovala ni u kakvoj vrsti sportskog programa. $\mathrm{Na}$ početku i na kraju istraživanja (nakon 10 dana škole vožnje rolera) ispitanici su testirani u šest (spust koso, zavoj brijegu, osnovni zavoj, plužni zavoj, paralelni zavoj od brijega i brzo vijuganje) prethodno izabranih elemenata tehnike alpskog skijanja. Svaki ispitanik je demonstrirao svih šest elemenata tehnike skijanja, a kosi spust i zaokret ka padini su izvođeni u lijevu i desnu stranu. Ispitanici su ocjenjivani na skali od jedan do pet od strane nezavisnih ispitivača. Primijenjena je standardizovana procedura ocjenjivanja (Cigrovski, Matković, B., i Matković, R.B., 2008). Program vožnje rolera trajao je 10 dana i podrazumijevao je dva nivoa. Nivo jedan sadržao je osnovne elemente vožnje rolera - bazično rolanje, kočenje, osnovni klizajući korak, odgurivanje sa oba stopala, osnovni A-zavoj, kočenje sa osnovnim A-zavojem i nivo dva koji je sadržao elemente tranzicije, trening samostalne vožnje rolera (vožnja rolera preko ulice i trotoara, zavoj sa odgurivanjem spoljašnjom nogom, paralelni zavoj, kočenje u T- 
položaju i kočenje za vrijeme paralelnog zavoja). Oba nivoa su kompletirana za vrijeme ciklusa od 5 dana, a obezbijeđena je sličnost uslova za sve ispitanike (isti broj ispitanika po grupi (10), broj sati dnevno provedenih u učenju vožnje rolera (1 sat), kvalitet rolera, iskusni instruktori vožnje rolera i odgovarajući teren za vožnju rolera). Dobijeni rezultati analizirani su statističkim paketom "SPSS for Windows 14.0". Distribucija rezultata testirana je Kolmogorov-Smirnov testom (K-S). Izračunati su osnovni deskriptivni parametri za šest elemenata kojima je testirana tehnika alpskog skijanja. Značajnost razlika u ocjenama dobijenim na procjeni tehnike skijanja između eksperimentalne i kontrolne grupe utvrđena je Mann-Witney U testom. Rezultati su bili značajni na nivou $p<0.05$. Značajnost razlika između dvije grupe ispitanika u umijeću skijanja utvrđena je t-testom sa nivoom značajnosti $\mathrm{p}<0.05$.

\section{REZULTATI}

U Tabeli 1 predstavljeni su rezultati deskritivne statistike na inicijalnom mjerenju eksperimentalne i kontrolne grupe

Tabela 1 Deskriptivna statistika inicijalne procjene umijeća skijanja

\begin{tabular}{llccccc}
\hline Grupa & & $\mathrm{N}$ & $\mathrm{M}$ & $\begin{array}{c}\text { Std. Error } \\
\mathrm{M}\end{array}$ & $\mathrm{SD}$ & $\begin{array}{c}\text { KS } \\
\text { test }\end{array}$ \\
\hline eksperimentalna & spust koso u lijevo & 72 & 3.90 & 0.07 & 0.60 & 0.00 \\
& spust koso u desno & 72 & 3.90 & 0.06 & 0.57 & 0.00 \\
& zavoj brijegu u lijevo & 72 & 3.45 & 0.10 & 0.85 & 0.00 \\
& zavoj brijegu u desno & 72 & 3.25 & 0.09 & 0.83 & 0.04 \\
& plužni zavoj & 72 & 3.52 & 0.09 & 0.81 & 0.04 \\
& osnovni zavoj & 72 & 3.20 & 0.10 & 0.89 & 0.02 \\
& paralelni zavoj od brijega & 72 & 3.20 & 0.10 & 0.89 & 0.01 \\
& brzo vijuganje & 72 & 2.82 & 0.11 & 0.98 & 0.00 \\
\hline kontrolna & spust koso u lijevo & 67 & 3.86 & 0.07 & 0.59 & 0.00 \\
& spust koso u desno & 67 & 3.85 & 0.06 & 0.56 & 0.00 \\
& zavoj brijegu u lijevo & 67 & 3.39 & 0.10 & 0.85 & 0.02 \\
& zavoj brijegu u desno & 67 & 3.18 & 0.09 & 0.81 & 0.02 \\
& plužni zavoj & 67 & 3.45 & 0.09 & 0.80 & 0.04 \\
& osnovni zavoj & 67 & 3.17 & 0.11 & 0.90 & 0.01 \\
& paralelni zavoj od brijega & 67 & 3.14 & 0.10 & 0.88 & 0.04 \\
& brzo vijuganje & 67 & 2.76 & 0.11 & 0.94 & 0.00 \\
\hline
\end{tabular}

N-broj ispitanika, M - srednja vrijednost, Std. Error M - standardna greška srednje vrijednosti, KS test - normalnost raspodjele

Rezultati pokazuju nešto bolje prosječne ocjene ispitanika eksperimentalne grupe u svim analiziranim elementima tehnike alpskog skijanja (Tabela 1).

Tabela 2 Razlika između eksperimentalne i kontrolne grupe u umijeću skijanja na inicijalnom testiranju

Element tehnike skijanja Mann-Witney U test Značajnost

Božić, Igor., et al. : Doprinos rolanja učenju...Sportlogia 2017, 13 (1), 1-8. Stranica 3. 


\begin{tabular}{lll}
\hline spust koso u lijevo & 2306.00 & 0.64 \\
spust koso u desno & 2300.00 & 0.62 \\
zavoj brijegu u lijevo & 2324.00 & 0.70 \\
zavoj brijegu u desno & 2297.00 & 0.62 \\
plužni zavoj & 2301.00 & 0.63 \\
osnovni zavoj & 2349.50 & 0.78 \\
paralelni zavoj od brijega & 2331.00 & 0.73 \\
brzo vijuganje & 2334.00 & 0.74 \\
\hline
\end{tabular}

Rezultati pokazuju da ne postoje razlike u prosječnim ocjenama ispitanika dvije grupe; stoga, na početku ovog istraživanja razlike u umijeću skijanja između dvije grupe ispitanika nisu postojale (Tabela 2).

Tabela 3 Deskriptivna statistika finalne procjene umijeća skijanja

\begin{tabular}{llccccc}
\hline Grupa & \multirow{2}{*}{$\mathrm{N}$} & $\mathrm{M}$ & $\begin{array}{c}\text { Std. Error } \\
\mathrm{M}\end{array}$ & $\mathrm{SD}$ & $\begin{array}{c}\text { KS } \\
\text { test }\end{array}$ \\
\hline eksperimentalna & spust koso u lijevo & 72 & 4.47 & 0.06 & 0.52 & 0.00 \\
& spust koso u desno & 72 & 4.41 & 0.06 & 0.56 & 0.00 \\
& zavoj brijegu u lijevo & 72 & 4.05 & 0.07 & 0.64 & 0.00 \\
& zavoj brijegu u desno & 72 & 3.99 & 0.08 & 0.69 & 0.01 \\
& plužni zavoj & 72 & 4.21 & 0.08 & 0.68 & 0.02 \\
& osnovni zavoj & 72 & 3.96 & 0.08 & 0.75 & 0.00 \\
& paralelni zavoj od brijega & 72 & 3.95 & 0.08 & 0.72 & 0.00 \\
& brzo vijuganje & 72 & 3.66 & 0.11 & 0.94 & 0.02 \\
\hline kontrolna & spust koso u lijevo & 67 & 3.86 & 0.07 & 0.59 & 0.00 \\
& spust koso u desno & 67 & 3.85 & 0.06 & 0.56 & 0.00 \\
& zavoj brijegu u lijevo & 67 & 3.39 & 0.10 & 0.85 & 0.02 \\
& zavoj brijegu u desno & 67 & 3.18 & 0.09 & 0.81 & 0.03 \\
& plužni zavoj & 67 & 3.45 & 0.09 & 0.80 & 0.04 \\
& osnovni zavoj & 67 & 3.17 & 0.11 & 0.90 & 0.02 \\
& paralelni zavoj od brijega & 67 & 3.14 & 0.10 & 0.88 & 0.01 \\
& brzo vijuganje & 67 & 2.76 & 0.11 & 0.94 & 0.00 \\
\hline
\end{tabular}

N-broj ispitanika, M - srednja vrijednost, Std. Error M - standardna greška srednje vrijednosti, KS test - normalnost raspodjele

Nakon 10 dana škole vožnje rolera, ponovo je procijenjena izvedba šest elemenata tehnike alpskog skijanja, a rezultati su predstavljeni u Tabeli 3. Ispitanici eksperimentalne grupe ostvarili su bolje rezultate u svim elementima tehnike skijanja. K-S test pokazao je da distribucija rezultata na finalnom testiranju nije u skladu sa propisanim kriterijumima.

Tabela 4 Razlika između eksperimentalne i kontrolne grupe na finalnom testiranju

\begin{tabular}{lcc}
\hline Ocijenjeni elementi & Mann-Witney U test & Značajnost \\
\hline spust koso u lijevo & 1086.50 & 0.00 \\
spust koso u desno & 1166.00 & 0.00 \\
zavoj brijegu u lijevo & 1382.00 & 0.00 \\
zavoj brijegu u desno & 1147.00 & 0.00 \\
plužni zavoj & 1151.00 & 0.00 \\
osnovni zavoj & 1242.50 & 0.00
\end{tabular}

Božić, Igor., et al. : Doprinos rolanja učenju...Sportlogia 2017, 13 (1), 1-8. Stranica 4. 
paralelni zavoj od brijega

1184.50

0.00

brzo vijuganje

1222.00

0.00

Rezultati predstavljeni u Tabeli 4 ukazuju na značajne razlike između ispitanika eksperimentalne i kontrolne grupe. Ispitanici eksperimentalne grupe ostvarili su više prosječne ocjene na svim testiranim elementima tehnike skijanja (Tabela 3), što upućuje na to da je škola vožnje rolera proizvela pozitivne efekte na učenje alpskog skijanja.

Tabela 5 Deskriptivni statistički parametri na finalnoj procjeni umijeća skijanja ispitanika eksperimentalne i kontrolne grupe

\begin{tabular}{lccccc}
\hline Grupa & $\mathrm{N}$ & $\mathrm{M}$ & Std. Error M & SD & KS test \\
\hline eksperimentalna & 72 & 4.09 & 0.06 & 0.54 & 0.41 \\
kontrolna & 67 & 3.29 & 0.09 & 0.80 & 0.53 \\
\hline
\end{tabular}

N-broj ispitanika, M - srednja vrijednost, Std. Error M - standardna greška srednje vrijednosti, KS test - normalnost raspodjele

Ukupno 72 ispitanika učestvovala su u školi vožnje rolera i ostvarili su bolje prosječne završne ocjene na procjeni umijeća skijanja (Tabela 5).

Značajnost razlika između grupa (4.09 vs. 3.29) testirana je nezavisnim t-testom.

Tabela 6 Razlike između grupa u umijeću skijanja

\begin{tabular}{lccc} 
& $\mathrm{t}$ & $\mathrm{df}$ & Značajnost \\
\cline { 2 - 4 } Završna ocjena iz & 6.96 & 137 & 0.00 \\
skijanja & 6.86 & 113.90 & 0.00 \\
\hline
\end{tabular}

Utvrđene su statistički značajne razlike između grupa u ostvarenom umijeću skijanja ( $p=0.00$, Tabela 6).

\section{DISKUSIJA}

Alpsko skijanje je specifična motorna aktivnost (Hoppeler i Vogt, 2009). Za razliku od skijaša takmičara u alpskom skijanju koji trebaju specifično kondicioniranje prije takmičarske sezone, skijaši rekreativci obično nisu dobro pripremljeni za specifična opterećenja za vrijeme skijanja (Stöggl, T., Schwarzl, Müller, Nagasaki, Stöggl, J., Scheiber, Schönfelder i Niebauer, 2016). Kondicioni trening uključuje vježbe za mišiće i zglobove koji će biti aktivni za vrijeme skijanja. Pored toga, treninzi kondicione pripreme usmjereni su na bezbjedno i brže savladavanje umijeća skijanja, kao i na prevenciju potencijalnih povreda za vrijeme padova ili sudaranja (Ekeland i Rødven, 2009; Hébert-Losier i Holmberg, 2013). Da bi program alpskog skijanja bio efikasan, nekoliko kriterijuma treba da budu ispunjeno, prvenstveno uslovi u kojima se program odvija, kvalitet instruktora skijanja, kvalitet programa, motivacija polaznika i instruktora skijanja i sposobnost polaznika škole alpskog skijanja da usvajaju nove aktivnosti (Barth i Bruhl, 2006; 
Lešnik i Žvan, 2010; Rausavljević, Vidamšek i Pišot, 2012; Cigrovski i Matković, 2015). Posljednje pomenuto korelira sa motoričkim sposobnostima polaznika, na šta može da se utiče prikladnim/adekvatnim kondicionim treningom. Rienhoff, Hopwood, Fischer, Strauss, Baker i Schorer, (2013) pokazali su da umijeća iz jednog sporta mogu biti od pomoći u savladavanju drugog, sličnog sporta. Programi alpskog skijanja za početnike obično su detaljno i pažljivo planirani (Lešnik i Žvan, 2010; Žvan, Lešnik i Supej, 2015). Baziraju se na šest ili sedam dana boravka u skijaškim centrima, sa unaprijed definisanim satima kada polaznici uče novu motornu aktivnost. Mnogo pažnje se posvećuje kreiranju idealnih programa škole alpskog skijanja, ali se mnogo manje zna o načinima pripreme skijaša rekreativaca za skijašku sezonu. Rezultati našeg istraživanja ukazuju da vožnja rolera doprinosi učenju alpskog skijanja. Naime, na početku našeg istraživanja ispitanici se nisu razlikovali u nivou umijeća alpskog skijanja, ali nakon 10 dana škole vožnje rolera, ocjenjivana izvedba elemenata škole alpskog skijanja pokazala je značajne razlike između ispitanika eksperimentalne i kontrolne grupe. Rezultati su pokazali bolje prosječne ocjene u svim analiziranim elementima tehnike alpskog skijanja za eksperimentalnu grupu, koja je pohađala školu vožnje rolera. Kroll, Schiefermuller, Birklbauer i Muller, (2005) ukazuju da zavoji kod vožnje rolera izgledaju vrlo slično skijaškim zavojima za vrijeme takmičarskog alpskog skijanja. Za očekivati je da bi se prilagođavanje na skije i skijaške zavoje brže i lakše ostvarilo ako rekreativci skijaši vladaju umijećem vožnje rolera. Pokazali smo da vožnja rolera na rekreativnom nivou doprinosi učenju alpskog skijanja kod mladih, motorički sposobnih osoba. Do sličnih rezultata došli su i Roman, Miranda, Martinez i Jesus, (2009) kod grupe djece uzrasta od 7 do 13 godina. Ispitanici iz pomenutog istraživanja pohađali su školu vožnje rolera prije učenja osnova alpskog skijanja i ostvarili su napredak u znanju alpskog skijanja, što je vjerovatno posljedica sličnosti kretanja u vožnji rolera i skijanja. Ispitanici iz našeg istraživanja su mlađe odrasle osobe, prethodno sportski aktivne, te bi bilo vrlo interesantno ispitati rezultate $u$ odnosu na druge populacije mladih osoba. Ako bi rezultati bili uporedivi između različitih populacija, vožnja rolera bi mogla da bude više primjenjivana u pripremnom periodu za alpsko skijanje. Prema Muehlbauer, Kuehnen i Granacher, (2013), vožnja rolera dva do tri puta nedjeljno po 90 minuta značajno doprinosi ravnoteži i snazi, koji su takođe vrlo važni za vrijeme inicijalne faze vožnje rolera, kao i kod usavršavanja umijeća skijanja. Štaviše, vožnja rolera pomaže razvoju kardiovaskularnih kapaciteta, što je važno u prevenciji povreda kod padova i sudaranja (Hébert-Losier i Holmberg, 2013; Philippe, Ruedl, Feltus, Woldrich i Burtscher, 2014).

\section{ZAKLJUČAK}

Vožnja rolera je praktična aktivnost koja lako može da se uklopi u svakodnevni raspored. Ako bi početnici u alpskom skijanju koristili vožnju rolera u pripremnom periodu za školu alpskog skijanja to bi im moglo pomoći da budu efikasniji u učenju osnova skijanja, ali i da napreduju brže u usvajanju elemenata tehnike alpskog skijanja. Ovo je ujedno i najpraktičnija primjena rezultata ovog istraživanja sa namjerom da rekreativni alpski skijaši koriste vožnju rolera i kao kondicioni trening za alpsko skijanje. 


\section{LITERATURA}

Barth, K., \& Bruhl, H. (2006). Training Skiing. Oxford, USA: Meyer and Meyer Sport.

Cigrovski, V., Matković, B., \& Matković, R.B. (2008). Evaluation of objectivity and homogeneity of skiing knowledge grading process. In D. Milanović, F. Prot (Eds.), $5^{\text {th }}$ International Scientific Conference on Kinesiology (pp. 513-517). Zagreb, RH: Faculty of Kinesiology.

Cigrovski, V., \& Matković, B. (2015). Skijaška tehnika-carving [Skiing technique-carving]. Zagreb, RH: Faculty of Kinesiology University of Zagreb.

Ekeland, A., \& Rødven, A. (2009). Injury trends in Norwegian ski resorts in the 10 year period 19962006. J ASTM, 5, 31-38. https://doi.org/10.1520/stp47463s

Hoppeler, H. \& Vogt, M. (2009). Eccentric exercise in alpine skiing. Chapter taken from Science and Skiing IV, 33-42. ISBN: 978-1-84126-255-0

PMCid:PMC2704421

Hébert-Losier, K., \& Holmberg, H.C. (2013). What are the exercise-based injury prevention recommendations for recreational alpine skiing and snowboarding? A systematic review. Sports Medicine, 43(5), 355-366.

https://doi.org/10.1007/s40279-013-0032-2

PMid:23463392

Kroll, J., Schiefermuller, C., Birklbauer, J., \& Muller, E. (2005). In-line skating as dry land modality for slalom racers-elektromyographic and dynamic similarities and differences. In E. Muller, D. Bacharch, R. Klika, S. Lindinger, \& H. Schwameder (Eds.), Proceedings from: The thirth international Congress on Skiing and Science (pp. 76-86). Oxford, UK: Mayer \& Mayer Sport.

Lešnik, B., \& Žvan, M. (2010). A turn to move on, theory and methodology of alpine skiing. Ljubljana, SLO: University of Ljubljana, Faculty of Sport. PMCid:PMC3295201

Muehlbauer, T., Kuehnen, M., \& Granacher, U. (2013). Inline skating for balance and strength promotion in children during physical education. Perceptual and Motor Skills, 117(3), 665-681. https://doi.org/10.2466/30.06.PMS.117x29z9 PMid:24665789

Philippe, M., Ruedl, G., Feltus, G., Woldrich, T., \& Burtscher, M. (2014). How frequent and why are skiers and snowboarders falling? Sportverletz Sportschaden, 28(4),188-192. PMid:25211310

Rausavljević, N., Vidamšek, M., \& Pišot, R. (2012). Igrom do prvih koraka na snijegu [Through play to first skiing steps]. Zagreb, RH: Croatian Olympic Academy.

Rienhoff, R., Hopwood, M.J., Fischer, 1., Strauss, B., Baker, J., \& Schorer, J. (2013). Transfer of motor and perceptual skills from basketball to darts. Frontiers in Psychology, 4, 593. https://doi.org/10.3389/fpsyg.2013.00593 PMid:24062703 PMCid:PMC3771373

Roman, B., Miranda, M.T., Martinez M. \& Jesus, V. (2009), Transfer from In-line skating to alpine skiing instruction in physical education. In Muller, E., Lindinger, S. and Stoggl, T. (Eds.), The fourth international Congress on Skiing and Science (pp. 430-439). Oxford, UK: Mayer \& Mayer Sport.

Ropret, R. (2010). The application of rollerblades in alpine skiers training. Physical culture, 64(1), 7278.

Stöggl, T., Schwarzl, C., Müller, E.E., Nagasaki, M., Stöggl, J., Scheiber, P., Schönfelder, M., \& Niebauer, J. (2016). A comparison between alpine skiing, cross-country skiing and indoor cycling on cardiorespiratory and metabolic response. Journal of Sports Science and Medicine, 15(1):184-95.

PMid:26957942 PMCid:PMC4763839 
Tate, D. (2007). Parallel dreams alpine skiing. Ireland: Parallel dreams publishing.

Žvan, M., Lešnik, B., \& Supej, M. (2015). Progressive increase in velocity, ground reaction forces, and energy dissipation in Alpine ski school elements. In E. Müller, J. Kroll, S. Lindinger, J. Pfusterschmied and T. Stoggl (Eds.), Proceedings from The six international Congress on Skiing and Science (pp. 354-358). Oxford, UK: Mayer \& Mayer Sport.

Wojtyczek, B., Pasławska, M. \& Raschner, C. (2014). Changes in the balance performance of Polish recreational skiers after seven days of alpine skiing. Journal of Human Kinetics, 44, 29-40. https://doi.org/10.2478/hukin-2014-0108

PMid:25713663 PMCid:PMC4327378

\section{SUMMARY}

Aim of this research was to determine contribution of inline skating to learning basics of alpine skiing. We included 139 participants, who were attributed to two groups - control and experimental. Participants of the experimental group $(n=72)$ were included in 10-days program of learning inline skating while participants pertaining to control group $(n=67)$ did not participate in any kind of sport or recreational program. Before and after inline skating, all participants were tested on six elements of alpine ski technique. Participants of the experimental group had better results on elements of alpine ski technique (4.09 vs. 3.29; $\mathrm{p}=0.00)$. Our results suggest inline skating aids better learning of alpine skiing.

Key words: inline skating, alternative sport, alpine ski knowledge 